\title{
Social Support for the HIVIAIDS Community: A Case Study of Komuniti Cakna Terengganu (KCT), Malaysia
}

\author{
Norizan Abdul Ghani (Ph.D)
}

Faculty of Applied Social Sciences, Universiti Sultan Zainal Abidin, 21300, Kuala Terengganu, Malaysia

Email: norizabd@unisza.edu.my

\section{Wan Mohd. Yusof Wan Chik (Ph.D)}

Faculty of Islamic Contemporary Studies, Universiti Sultan Zainal Abidin, 21300,

Kuala Terengganu, Malaysia

\section{Berhanundin Abdullah (Ph.D)}

Faculty of Islamic Contemporary Studies, Universiti Sultan Zainal Abidin, 21300,

Kuala Terengganu, Malaysia

\section{Farah Syazrah Mohd. Ghazalli}

Faculty of Applied Social Sciences, Universiti Sultan Zainal Abidin, 21300,

Kuala Terengganu, Malaysia

Doi:10.5901/mjss.2015.v6n1s1p232

\section{Abstract}

Social support is the perception and actuality that one is cared for, has assistance available from other people, and that one is part of a supportive social network. These supportive resources can be emotional, financial assistance, informational or companionship and also intangible. Social support can be measured as the perception that one has assistance available, the actual received assistance, or the degree to which a person is integrated in a social network. Support can come from many sources, such as family, friends, pets, neighbours, coworkers, organizations, etc. Those who receive social support will feel relaxed and loved. This study will discuss the support carried out by the NGO, Komuniti Cakna Terengganu (KCT), to HIVAIDS sufferers. KCT was established through an initiative from some former drug addicts who have been marginalized by their families and community. The focus of this study is to examine social support for HIV-AIDS patients and is limited to the role played by KCT. The objectives of this study are to analyze the views of patients with HIVIAIDS who received social support and to identify the obstacles faced by KCT in continuing support for the group. This study used the qualitative method with two techniques to get data; Focus Group Discussion (FGD) and observation. 18 respondents were involved in two FGD sessions. The study found that all patients are satisfied with the support given to them be it spiritual, informational or intangible. The programs are very effective and should be continued. Patients feel appreciated and gain more understanding about religion. To the respondents, religion becomes a filter for all negative things. There is a need for more NGOs such as KCT to provide support to marginalized groups such as the respondent. Government and private agencies and other NGOs should provide support in all forms to NGOs such as KCT.

Keywords: Social Support, HIVIAIDS Patients, Komuniti Cakna Terengganu, NGO

\section{Introduction}

The report released by the National Institute on Drug Abuse (2003) 1st Edition, Drug Prevention Program among Children and Adults, said prevention programs work at all levels of the community, including through civic, religious, law enforcement and government organizations to boost anti-drug culture and prosocial behavior. All levels of society and government organizations need to play a part, including running new policies such as drug-free schools, or strengthening community practices. Many of the programs are able to become a medium to consistently communicate through programs in schools, workplaces, religious institutions and the media. Studies have shown that prevention programs involving youth using a variety of sources can have a strong effect on the community's norms. Social support from all 
parties will accomplish the objectives of drug prevention.

Social support is the perception and actuality that one is cared for, has assistance available from other people, and that one is part of a supportive social network. These supportive resources can be emotional, financial assistance, informational or companionship as well as intangible. Social support can be measured as the perception that one has assistance available, the actual received assistance, or the degree to which a person is integrated in a social network. Support can come from many sources, such as family, friends, pets, neighbours, co-workers, organizations, etc. Those who receive social support will feel relaxed and loved.

\subsection{Community role in providing social support to those in need}

The role of local communities should be harnessed for the sake of strengthening the social life in a community. Community involvement can give a definite influence towards the drug problem in a community (Ahmad Shukri Nain, 2004).

In Malaysia, the level of social support from the community is still discouraging. Those in need of social support such as former drug addicts or HIV-AIDS patients suffer the same fate; often marginalised. This is proved by the study of relapse among drug addicts who came out of the prison. Based on the study done by Fauziah Ibrahim (2012), Drug Addicts and the High Risk of Returning to Relapse (Penagih Dadah dan Keadaan Berisiko Tinggi Kembali Relaps), she concluded that addicts show a high tendency to relapse and take drugs if they experience negative emotions such as anger, frustration, sadness, depression and boredom which leads to a high rate of relapse. Social pressure from their surroundings and interpersonal conflicts such as misunderstandings with friends, family, marriage and society around them are also a few of the factors that will affect drug addicts to relapse.

The community needs to consider various ways to help those left outs; for example by establishing homes or community services centers that are conducive for the former drug addicts and HIVIAIDS patients to live in.

A study done by Ruhani Mat Min (2012) on Community Centers: Partial Recoverey Addicts Rehabilitation Program concludes that information about the Community Centre should be propagated as the result shows that the community is ready to engage with the former drug addicts and HIVIAIDS patients. Promotions or publicity of the Community Centre's facility or service must be made on a large scale. Committee members involved should also publicize the Community Centre's activities to the community and encourage community members to participate in activities organized by the Community Centre focusing on society in general. Activities held in the community centre are open to all members of its society. The purpose of this activity is to strengthen the relations between members of the community and the former drug addicts and HIVIAIDS patients. It is assumed that the 'sense of belonging' and close relationship between them can avoid community from any negative conduct.

\subsection{Komuniti Cakna Terengganu (KCT)}

This study will focus on the role played by KCT in providing support to the respondents. The challenges faced by KCT will also be discussed. KCT is registered under the name of CAKNA Community Organization of Kuala Terengganu District, Terengganu (KCT). It is mostly known as CAKNA Terengganu and it's registration was approved on the 21.12.2009. KCT's vision is to reduce the harm caused by drugs \& HIVIAIDS in the community. KCT's mission is to be the leading organization in harm reduction, as a result of Drugs \& HIVIAIDS in Terengganu. Government agencies that have been helping to achieving this vision and mission, include; the Ministry of Health Malaysia (MoH), the Department of Social Welfare (JKM), Terengganu, Religious and Malay Customs Terengganu (MAIDAM), Royal Malaysian Police (PDRM), State Department of Agriculture, KPWKM, LPPKN, the National Anti-Drug Agency (AADK) and other departments, agencies and individuals.

Up to now, KCT has two temporary shelters which include Baitul Cakna for Men (Baitul Cakna Lelaki-BCL) and Baitul Cakna for Women. These centres or houses are called home by a number of HIVIAIDS patients and those with a high risk of getting infected who have no where to go or stay. BCL was established for the purpose of:

- Providing temporary shelter for men with HIVIAIDS and those who are at a high risk for infection and homelessness

- Providing a safe and comfortable environment for occupants

- Ensuring good care for sick occupants

- Ensuring compliance with treatment and medication schedule of its occupants

- Applying a religious life and values for residents

- Providing occupational therapy to occupants 
- Teaching residents about self-management, time and finances

- Providing knowledge and skills in agriculture to residents

There are 12 rules that have been set by the Baitul Cakna committee to its residents. Regulations must be adhered to its residents and those rules and regulations include; no drugs, no fighting and no stealing. Their daily routine starts as early as $5.00 \mathrm{am}$ to get ready to perform the Subuh prayer at the mosque. After morning prayers, they talk about the greatness of Allah SWT, read the interpretation of the Quran, read books related to being patient, tawakkal and redha (acceptance). Moreover, they are also trained to speak up to boost their self-confidence. They are required to talk about gratitude, thankfulness and forgiveness.

BCL was established on December, 23rd 2010. The land used to build BCL belongs to a senior doctor involved in the KCT project. Initially, there were only three occupants at BCL and it only focused on the users of methadone (drug replacement medication that has been approved by the Malaysian government). However, the number of methadone users that are committed to it is too difficult to find. Therefore, KCT decided to change its target, focusing on drug users, drug addicts, those who are homeless, those who just came out of the rehabilitation centres, prisons or those who are not accepted by their family members and those who really want to stop and change on a voluntary basis.

$\mathrm{BCL}$ does not adhere to the concept of new and old (or junior and senior), but more to a brotherhood and sisterhood concept - as if they are of the same family, as a family. As of today, Baitul Cakna for Men (BCL) only accepts Muslim members.

\section{Significance of Study}

This study was conducted to provide information to the community that there are organizations like $\mathrm{KCT}$, helping secluded or marginalised groups such as the respondents. KCT and the respondents require ongoing social support from all sides be it the government or private sectors, NGOs as well as the community.

\section{Literature Review}

Edwin Wouters Dingie Janse van Rensburg (2010) described that recent studies suggest that community mobilization can be at least part of the solution to the unavailability of health professionals for HIVIAIDS care. First, community initiatives-such as community health workers, treatment buddies, and patient support groups-can increase the effectiveness and efficiency of public-sector treatment efforts. Community care providers broaden HIVIAIDS care beyond mere medical tasks by providing social support and counseling. In this way, community initiatives meet the emerging needs associated with chronic AIDS care, where health professionals' roles are becoming progressively limited to technical medical and nursing tasks. Second, communities themselves should be seen as an integral part of the response to HIVIAIDS. We stress the importance of transforming social structures to create communities that recognize the reality of HIVIAIDS and share knowledge and skills to create environments in which people can engage in protective behavior and support their fellow community members in need. Communities can thus be considered an underexploited resource in building and strengthening the care capacity needed to successfully scale up chronic disease treatment in resourcelimited settings.

Ameneh Setareh Forouzan et al (2013), considers social network interactions as a potential source of support for individuals living with HIVIAIDS in Iran. This cross-sectional study was conducted on 224 people with HIVIAIDS who refer to behavioral counseling centers. Participants were randomly selected among all people with HIVIAIDS from these centers. Relatives were reported to be a source of support more than nonrelatives. They were closer to participants, but there was a difference between the closest type among relative and nonrelative supporters. Mean of functional support with considering the attainable range 0-384 was low after being adjusted for other variables in the final model. Totally, in this study, many of the participants had the static social support network that contained large proportions of family and relatives. The findings contribute to the evidence for promotion of knowledge about social support network and social support of people living with HIVIAIDS.

AIDS is a disease that affects not only the physical health but also mental and social conditions of patients because of the negative attitude of society, discrimination, and stigmatization especially in the developing countries. People living with HIVIAIDS (PLWHA) may experience social drift, changing patterns of sexual behaviors and self-image. They may lose employment, financial resources, and even family and friends as major sources of support. Approximately 22,727 cases of HIVIAIDS have been identified in Iran. It is estimated that this number will increase to 106,000 patients up to 2015. On the other hand, due to progress of antiretroviral therapy that increases life expectancy in patients, improvement of the quality of life in PLWHA is important. Previous studies suggested that social support can be an 
important factor for influences on well-being and quality of life. Researchers have provided evidence that social support as an aspect of psychological adjustment can improve physical and psychological health outcomes, increasing motivation for treatment, self-care behaviors, and also prevention of transmission of infection during HIVIAIDS disease. Many PLWHA may facilitate living with HIVIAIDS by their social support networks (SSN). SSN as a subset of a larger social network, consisting of some individuals who are linked to ego and roles such as emotional support, financial aid, guidance, and advice offered to him/her in a variety of situations. SSN is assumed to be stable in terms of size, composition, and resources of support, except in times of developmental transitions or nonnormative life changes, such as loss and diseases. Network studies have shown that family, friends, and relatives are important sources of social support that can provide the different types of support. But the literature has shown that the size of social support networks for PLWHA was smaller than non-PLWHA, and that this change can directly affect the amount of social support provided. Despite the growing body of literature on the concept of social support, there is little information about the structure and function of SSN and related factors among the PLWHA in Iran. The aim of the study was to determine characteristics of SSN and associate these characteristics to social support among PLWHA.

HIV is a major public health problem in the world, especially in sub-Saharan Africa. It often leads to loss of productive labour and disruption of existing social support system which results in deterioration of population health. This poses a great challenge to infected people in meeting their essential goods and services. This study examines health and social support services provided by employers to HIVIAIDS infected employees in Tanzania. A total of 181 employees and 23 employers from 23 workplaces aged between 18-68 years were involved. The results show that $23.8 \%$ (i.e., $20.4 \%$ males and $27.3 \%$ females) of the employees had at least one member of the family or close relatives living with HIV at the time of the study. Fifty six percent of the infected employees reported to have been receiving health or social support from their employers. Employees' responses were consistent with those reported by their employers. A total of $12(52.2 \%)$ and $11(47.8 \%)$ employers reported to have been providing health and social supports respectively. Female employees (58.3\%) from the private sector $(60.0 \%)$ were more likely to receive supports than male employees (52.6\%) than those from the public sector (46.2\%). The most common health and social support received by the employees were treatment, and nutritional support and reduction of workload, respectively. As a conclusion, HIVIAIDS infected employees named treatment and nutritional support, and soft loans and reduced workload respectively, as the most important health and social supports they needed from their employers. This study provides baseline information for further studies on provision of health and social support services by employers to HIVIAIDS infected employees in the context of a developing an economy like Tanzania (Telemu Kassile, 2014).

Rachel M. Amiya, et al. (2014) in her study 'Perceived Family Support, Depression, and Suicidal Ideation among People Living with HIVIAIDS: A Cross-Sectional Study in the Kathmandu Valley, Nepal stated that overall, 25.5\% of participants registered $\mathrm{BDI}$-la-defined depression, with significantly lower rates among those with perceived family support scores in the highest $(A O R=0.19 ; 95 \% \mathrm{Cl}=0.07,0.55)$ and middle $(A O R=0.38 ; 95 \% \mathrm{Cl}=0.17,0.86)$ tertiles relative to those with lowest-tertile scores. Meanwhile, $14.0 \%$ reported suicidal thinking, with significantly lower rates among those in the highest perceived family support tertile relative to the lowest $(\mathrm{AOR}=0.25 ; 95 \% \mathrm{Cl}=0.07,0.91)$. Broken down by support sub-scale, only negative support (i.e. family difficulty) was significant in its correlations with both outcomes - a trend similarly reflected in the item-wise analyses. The findings highlight an important role for family support in determining experiences of depression and suicidality among PLWHA. Incorporating family counseling and support services - with special focus on ameliorating negative interaction and bolstering emotional support - into HIV care and treatment services may help to improve mental health along with overall wellness and treatment outcomes for HIVpositive populations in Nepal and similar settings.

Negative influences growing up were also discussed by Gabriele Schafer (2011) in his study titled Functional Family in Family Alcohol and Drug Addicts. The study found four themes that were the reason for opiate users that experience trauma during childhood and the difficulties of life during adulthood, relationship conflict with parents since young adulthood, psychological disorders in contact with the couple, and disturbances in the parents' role. In short, all opiate users initially failed to build good relationships with family

A study entitled social support to opiate users among the Malays, Chinese and Indians in Malaysia by Wan Rafaei et al., (2009) looked at the kind of support received by opiate users in rehabilitation centres in three major races in Malaysia. The study found that all races agreed that lack of family support is the cause of failure to recover from drug addictions besides other factors - programs practiced in rehabilitation centres, boredom after they complete the program as well as peer influence. In terms of social support, there are a number of social support aspects that had been identified such as socialization supports, emotional supports, practical assistance, financial assistance as well as advise and guidance. The report also studied the differences between a group of opiate users and a group of university students who were not addicted to drugs. The study found that there are gaps between both groups where the university students have 
higher social support from family than those who are of the other group. The opiate users were found to have low social support from their family which then discouraged them and made them to have low self-esteem.

Dedi Afandi et al., (2009) also agreed that the relationship built out of social support from family do affect drug addicts' changes. Their studies looked at the relationship between family's social support with Drug Abuse Screening Test-10 (DSAT-10) among adolescents in one secondary school in Pekanbaru, Indonesia. This study utilizes Adolescent Social Support (ASS), which consists of three domains which includes family support, school environment and peer support. The study used SPSS for data analysis where Pearson correlation Test and $t$-test were used to examine the relationship between social support to all three domains. The study found that the family's support domain and school's environment domain have a close relationship with DSAT-10. This shows that acceptance and support of family can help adolencent overcome drug addiction. The school environment, on the other hand, plays an important role to protect teenagers from becoming involved in drug abuse and addictions. It was also found that there is a significant relationship between peer support and DSAT-10. Through this study, it can be seen that social support through active involvement can provide emotional relief to opiate users as well as encourage them to change.

A study entitled Drug Addiction among Malays by Hasnah Ibrahim (2010) stressed the importance of the community in returning to the path of true Islam (sirotalmustaqim). Despite the fact that many NGOs and governmental bodies take action in fighting drugs, the number of drug addicts among Malays are still high. She suggested that the community should come back to the nature of Islamic teachings - brotherhood as one of the efforts to curb the negative social influences especially in term of drug abuse.

Findings from a survey assessing the beliefs regarding testing, confidentiality, disclosure, and environment of care and attitudes towards the care of people with HIVIAIDS (PLHWA), in 1020, 4th and 5th year medical students, from public and private medical universities in Malaysia revealed that less than $20 \%$ of medical students received adequate training to care for PLHWA. They had prevalent negative beliefs regarding testing, confidentiality, disclosure and environment of care towards PLHWA although in giving care to PLHWA, their attitudes were largely positive and nondiscriminatory (Koh Kwee Choy et al, 2013).

\section{Objectives of the Study}

The focus of this study is to examine social support for HIVIAIDS patients and is limited to the role played by Komuniti Cakna Terengganu (KCT). The objectives of this study are to analyze the views of patients with HIVIAIDS who received social support and to identify the obstacles faced by KCT in continuing its support for the group.

\section{Methodology}

This study used the qualitative method with two techniques to get data; Focus Group Discussion (FGD) and observation. 18 respondents were involved in two FGD sessions including three who are doing managerial work for KCT.

\section{Findings}

\subsection{Views of patients with HIVIAIDS Who Received Social Support}

Through two FGD sessions, this study found that all patients are satisfied with the support given to them; be it spiritual, informational or intangible. According to R4, R5 and R6, they feel very grateful to become KCT members and lived in Baitul Cakna Lelaki (BCL).

"When they're in BCL, they found a new life. Not only that they are accepted by the community, but they also live as a family" (R4, R5 and R6).

"We're like siblings. Yes, everyone is concerned for one another (brotherhood). We often threat the new comers (drug addicts) based on their individual condition. When they first came in, usually they will suffer pain in their bodies, we'll just let them be, give them some space, means we will give them supports, for example encouragements. That's normal, first day; second day and third day here their bodies will ache. Mainly depends on how much they use drugs, for example vomiting, and all, some of them cannot even stand up straight, so we give them time to heal until they are okay, two weeks tops. When they start eating, and everything is good, they have the energy, then everything will be OK" (R10). 
The community in Kampung Baru, Ajil accept them whole-heartedly whenever there are programs organized by the villagers, they will also be invited. For example, programs like spring cleaning or gotong royong, ta'lim event, Surah Yasin recitation and so on. Such a community spirit should be made an example by every community in all other places in Malaysia.

"If there are activities organized by the local community here, residents of BCL will be invited to join the community" (R3).

"Sometimes they will inform us. When they do, for example, if we were to go to our vegetable garden to pick long beans in the morning, and someone came to inform us about their programs being held by the mosque for example, we will make them our first priority. It's something you do when you live in other people's village, we need to maintain a good relationship. We're like the mosque's adopted children" (R8).

"We have also been invited to wedding ceremonies, funerals, tahlil, they will inform and ask us to join" (R10).

\subsubsection{Spiritual}

The focus or goal of the activities carried out by KCT for BCL is to create an atmosphere of religious brotherhood (unity) between the occupants despite the fact that there are some of them who come from outside of Terengganu such as Pahang, Kelantan and Kedah. In addition to maintaining relationships among members, the activities carried out are also more focused on fostering brotherhood with the local community. They practice congregational prayers in the mosque five times a day and keep in touch with the committee members of the mosque. The mosque committee members are very welcoming and they often invite them to participate in community activities such as gotong-royong to clean the cemetery ground.

Residents of $\mathrm{BCL}$ are also taught about theology by two local religious teachers. The knowledge taught is about repentance, patience, fardhu ain such as obligatory prayers, Quranic recitation and self-reflection. Every day, they also practice the last 10 chapters of the Quran daily. Among the activities carried out at BCL include cleaning up the village's mosque as well as sessions with the residents of BCL.

Many residents agreed that the religious program practiced at $\mathrm{BCL}$ is better than other programs practiced in rehabilitation centres or prisons.

"Most of us were out from rehab or prisons....so we...if...to simplify this...the programs they offered in prisons...especially in rehab, the religious program is strict...strict...aa..too packed, so it can be said that most of us are not good at, but the basics we're all well aware of it." (R7, R10, R11).

"At BCL, the religious program is a priority. Whatever that we do, we have to make sure that religion or faith comes first. We practice the concept of family...so we help and advise each other. Those who were advised need to accept it wholeheartedly..we are helping each other without expecting something in return. Life here is based on the concept of love." (R10)

"We've learned so many things here, there are residents who are assigned to talk about the greatness of Allah SWT. This is crucial because we have to get rid of the self-greatness in our hearts. Those who were assigned, need to wake the others up, for prayers. Those who are assigned in the kitchen will cook food. We organize our schedule every day" (R12).

Patients feel appreciated and gain more understanding about religion. To the respondents, religion becomes a filter to all negative things.

\subsubsection{Informational (Agriculture, Life Skills, Softskills etc.)}

Information on skills is to be given to the residents or occupants of BCL. KCT has received much support from government agencies such as the Department of Agriculture to train residents on how to work on their own farm in the backyard. "We are more into gardening. So, the income we get from it is used to manage this house" (R7).

"We are currently working on our farm and are involved in KCT voluntary works" (R4).

"We will find any wholesalers, usually we already have someone... No... we will send it... The income we get from this

will be used for house necessities, in terms of expenses... expenses are managed by the house's management" (R6). 
For R4, he has had a skill in wiring and is interested in engineering. When he is cured and no longer bound by drugs, he aims to open his own wiring workshop.

Observation showed that all the respondents were satisfied with the informational guidance they received from all parties during their stay at BCL.

\title{
6.1.3 Intangible (Emotional, Moral, Peer Supports)
}

Many studies show emotional, moral and peer support are essential and contribute to the well-being of HIVIAIDS patients, drug addiction and alcoholism is acknowledged to affect all BCL's residents.

All residents who were interviewed agreed that it is comfortable to live in BCL. BCL made their life more meaningful. Their relationship between the families has also improved.

Some of the residents will go home every month to meet their mothers. "When we do not go back home for so long, we will really miss our mother. I hope one day I can get back up again and build my own business. But before that, I need to be spiritually strong. My mom is the most encouraging person and that is why I want to change towards the better" (R4).

$\mathrm{R} 8$ is active when it comes to voluntary works in KCT. KCT take friends of $\mathrm{BCL}$ as their own family, place for them to share their ups and downs besides themselves. They are their own encourager to motivate them because courage to change comes from within."There is no stigma. It takes a whole lot of hope, because not all of us are happy with it, so we make ourselves prepared to meet the outside world. We have to set it from the beginning, what people think of us. We have to be strong. We keep on praying that they would accept us just the way we are, we need the support to continue on living a normal life."

\begin{abstract}
"Yes, my wife's support and I as well, it's like a back-up plan, support system. I've talked from the moment I first stayed here, the first time I came in; the local community was very supportive Alhamdulillah, because we ourselves want to spend time with the community. Of course there'll be those who do not fancy you, it's a fact we cannot deny but we have to see it either way.. But the mosque's committee accepts us" (R8).
\end{abstract}

"All praises to Allah SWT, we have our brothers to encourage us. Give support, which is the most important thing to us" (R6).

"We're alike.... since we're Malays, we show some respect to the elders, the young respects the old, but in terms of rehabilitation like what Abang Din mentioned earlier it is actually the same, no differences, it's just that we still apply the Malay norms" (R14, R 15, R16).

"Actually most of us are like that, myself for example, I had been in jail and rehabilitation centres for years, my body is fully recovered. But when I am to deal with acceptance, it's very hard for me to be accepted within the community, there's no right way to mix in. So, that is why most of us became addicted again (drug addiction) (R6).

"When I first came in, it's already completed. It was all because of the management, the superiors. We have 3 staff here, Mr. Amran, Abang Din earlier and another one, Mr. Anuar he has some work to do outside, for Men's Baitul Cakna $(B C L)$. The others they have other staff from associations" (R7).

"I'm married with 4 children. I've been here for 5 months. I came in voluntarily. Because at my age, I'm getting older, almost 40 years old, I was at my worst before, severely addicted to drugs.... until I forgot my responsibilities and it was my wife who gave me support...means, l've supports from both my wife and parents" (R9).

"Actually, I was just squatting, but sooner or later I decided to stay permanently here and it has been a year" (R10).

Pertaining to peer support, a respondent said: "We practice volunteerism, we don't push them but we welcome them... if they can come in a good way, they will go home in a good way...If there is one of us who loves to sit alone we will approach him and be a good listener, give encouragement. Because these types of people, people like us, can't be ignored and left alone, we have to be in a group. We're like threads, when we pull one piece of thread, it will break, but when we pull a bundle of them....aaa....it's hard" (R8).

In general, it can be said that all of the residents of BCL agreed that all programs offered there are very effective and should be continued. 


\subsection{Obstacles faced by KCT in Continuing Support for the Group}

\subsubsection{Financial support}

Finance is a key requirement for any organization. KCT is trying to get funds from contributors as efficiently as possible, but one of the few the challenges is less cooperation and support from them.

"We need support to earn money. We have plans and recommendations but it is not yet applied, such as enlarging this place. But usually, when it comes to improvements, the management will agree with us" (R6).

In 2014, KCT has some financial problems as the major contributor, MAIDAM had not come up with a confirmation letter. MAIDAM usually contribute up to RM80,000.00 to Baitul Cakna for Men (BCL) and more than RM200,000.00 to Baitul Cakna For Women. It is still enough for now.

The Social Welfare Department (SWD) is rather difficult when it comes to approving the applications as they are bound by certain rules. However, the Ministry of Health provides free medical treatment to all members of Baitul Cakna.

Salaries paid to KCT's staff come from the contributions of several NGOs and agencies such as Global Finance and Project Alliance.

The Terengganu State Government gave nine acres of land in Hulu Terengganu and KCT plans to plant tapioca and oil palm on a large scale.

\subsubsection{Stigma and Prejudice Towards HIV/AIDS Patients.}

The community's stigma is a major threat faced by drug addicts and people with HIV / AIDS worldwide. Stigma against people living with HIVIAIDS becomes a barrier to those who want to give support to people with HIVIAIDS. Ajil's communities, however, provide good support.

Sometimes, some departments and agencies do not fully support BCL due to the reasons mentioned above. For example: Services given to the respondents by some departments were biased and they were not treated like everyone else even if disabled.

Sometimes the hospital itself treats HIVIAIDS patients as second class patients. There are times when the hospital chooses to send HIVIAIDS patients who are bedridden to be cared for by BCL. Unfortunately, there were no facilities given to $\mathrm{BCL}$. There are cases where KCT is forced to give patients to other treatment centres.

"Istana Budi in Rawang, Selangor also plays an important role in exchanging points of view with KCT" (R2).

It is crucial that the Islamic Religious Department helps provide a comfortable welcoming rehabilitation centre to bedridden patients.

\subsubsection{Lack of Support from Other Agencies or NGOs}

New NGOs such as KCT desperately need the support of other parties, especially among NGOs. But the result of interviews and observations conducted found that KCT has not received support from any party. There was lack of support from other NGOs because KCT offers different necessities than other centres, except Inabah, one of the rehabilitation centres for drugs.

"KCT needs to work extra hard in order to get support from NGOs or other agencies be it in Terengganu or outside. There are a number of NGOs who came to see how KCT manages BCL. We have to give full cooperation because we believe that it will benefit our belief, community and country as a whole" (R2).

\subsubsection{Lack of Volunteers}

Observations and interviews have shown that people do not cooperate in voluntary work with KCT. Volunteers who work are those who have been involved in drugs and people with HIVIAIDS. Lack of volunteers from the community to engage in volunteer work would surely affect KCT goals to help these groups of people.

"We really appreciate graduates/ students, on behalf of the community who support us as well as always ready to do 
voluntary work if needed by KCT. Those who still have a stigma towards drug addicts and HIV/AIDS patients, however, they are still struggling when it comes to joining our activities." (R3)

For now, KCT is still relying on the volunteers from their staff as well as BCL residents. Some of them confessed that they will become volunteers forever for KCT. "If lets say one day we no longer stay here, we would volunteer when we're needed, for voluntary works. That's what we want, we don't want to get out of the group. Though we're cured, we will still help and support" (R4, R12, R17, R18)

\subsubsection{No Future Leaders}

Through our observation, KCT is in need of figures who can take the responsibility to lead the body. There are two to three leaders who are very committed to the survival of KCT. Mr. A and Mr. B are among KCT's volunteers to manage and take care of the affairs of the residents of KCT.

Observation also showed that the manager or the leader of KCT efficiently carries out all tasks and most of the tasks were successfully done. For example, in financing KCT, let it be in terms of financial assistance or technical assistance from government agencies and the private sector, all went well in KCT although much redtape was found at the agency.

\footnotetext{
"We felt that if KCT does not recruit future leaders for KCT, it is a great loss to the marginalized communities such as drug addicts and HIVIAIDS patients."

"We need a competent manager to manage KCT. We will not be here forever because we have our own family. One day, we will leave KCT to be led by its future leaders." (R1, R2, R3)
}

\subsubsection{Lack of Promotion}

As an NGO, that lacks in almost everything, KCT strives to bring the organization into the eyes of the community and government. It aims to provide confidence that $\mathrm{KCT}$ is trying to help the marginalized community consisting of drug addicts and HIVIAIDS patients. This would help KCT when seeking cooperation and assistance from the relevant authorities for the survival of the organization. Promotions were also made but have not yet achieved an effective level. The community has yet to recognize KCT in a closer way. Many HIVIAIDS patients are interested in getting support from KCT but they do not know how to apply. A resident of BCL said:

"I just got out of prison, I've no family, parents... I was in the city all alone without reasons...then I found this pamphlet. I found it and from that, I headed straight here to BCL" (R6).

The secretary of KCT also said that they are putting every effort needed to inform and promote the existence of this organization to all parties. There are, however, several government and private agencies that have provided assistance to KCT such as MAIDAM and the State Department of Agriculture.

"These agencies provide assistance through financial support and skills to KCT and BCL residents." (R1)

\subsubsection{Lack of Complete and Conducive Facilities}

The survey was conducted on rented premises for KCT to operate and built shelters and gives the impression that they are not getting proper facilities. There are cases in which the government hospital wanted to place bedridden patients at $\mathrm{BCL}$ but unfortunately had been rejected because there is no medical facility; i.e. a comfortable bed and insufficient staff and medicine.

\footnotetext{
"We are in dire need of a conducive accommodation if any. In such a condition - lacks, KCT cannot accept bedridden patients. It will make them suffer more than they already are" (R2).
}

Interviews and observations found that KCT only rent one part of the premises in a relatively limited area. $\mathrm{BCL}$ is just a small barn and a house that does not have complete equipment, let alone a comfortable bed. However, all residents who were interviewed in $\mathrm{BCL}$ agreed that they feel grateful for what they have. They believe that their happiness does not lie in the facilities provided but it comes from the support and love of its residents. 
"We really love staying here. We're like brothers, sharing our ups and downs.... We are happy here" (R12, R15, R18).

It is crucial that agencies like KCT and homes like BCL are provided with conducive accommodation for the sake of the well-being of the people, especially these marginalized groups of drug addicts and HIVIAIDS patients.

\section{Conclusion and Suggestions}

The role played and contributions by NGOs such as Komuniti Cakna Terengganu (KCT) is enormous not only to marginalised groups such as people with HIVIAIDS but also to the community and the government. Although the government has been trying their best to improve and enhance community awareness about drug prevention programs in an effort to prevent the community from being involved with drugs which then can lead to HIVIAIDS, the effect has been less than impressive. Stigma still exists against these marginalized groups. No doubt there are communities that play a role in providing support to this group. When communities have already initiated steps, continuous monitoring should be done to ensure that the program carried out by the community is continuous.

There is a need for more NGOs such as KCT to provide support to marginalized groups such as the respondents. Government and private agencies and other NGOs should provide support in all forms to NGOs such as KCT.

\section{Acknowledgement}

This work was funded by the Niche Research Grant Scheme (NRGS - grant number UniSZA/NRGS/2013/RR057/2), The Ministry of Education, Malaysia (KPM). Special thanks to KPM and University Sultan Zainal Abidin (UniSZA), Terengganu, Malaysia.

\section{References}

Ahmad Shukri Mohd Nain, Paimah Atoma and Rozeyta Omar. (2004). Persepsi Penagih opiat, Ibubapa dan Masyarakat Terhadap Dadah. Seminar Antarabangsa Nilai dalam Komuniti Pasca Modenisme (Sivic 2004).

Alberta Health Services. 2010. Community Action on Drug Abuse Prevention in User Manual. USA.

Ameneh Setareh Forouzan et al., Social Support Network among People Living with HIVIAIDS in Iran. AIDS Research and Treatment, Volume 2013, Article ID 715381, p. 1-7, Hindawi Publishing Corporation, http://dx.doi.org/10.1155/2013/715381

Dedi Afandi, Fifia Chandra dan Lilik Kurniawan. (2009). Correlation between Social Support and Drug Abuse Screening Test Test-10 among Senior High School Students at Pekanbaru District, Riau Province, Indonesia. Jurnal Ilmu Kedokteran, Jilid 2 Nombor 1, ISSN 1978-662X.

Drug Reports for November and December, 2013. Agensi Antidadah Kebangsaan. Putrajaya. www.aadk.gov.my

Edwin Wouters, Dingie Janse van Rensburg (2010). Role Of Communities In HIVIAIDS Care. Health Affairs, 29, No. 6. 1275. DOI: 10.1377/hlthaff. 2010.1513

Gabriele Schafer (2011). Functional Family in Family Alcohol and Drug Addicts. http://www.tepou.co.nz/library/research/921

Hasnah Ibrahim (2004). Drug Abuse Among The Malays. Kolej Universiti Islam Malaysia. Unpublished PhD Thesis.

Jacqueline Barnes et al, (2006). Children and Families in Communities: Theory, Research, Policy and Practice. Hoboken: Wiley.

Koh Kwee Choy et al., Beliefs and Attitudes of Medical Students from Public and Private Universities in Malaysia towards Individuals with HIVIAIDS. The Scientific World Journal, Volume 2013 (2013), Article ID 462826, 8 pages http://dx.doi.org/10.1155/2013/ 462826

Niza Samsuddin et.al, Social and HIVIAIDS Risk Behaviours in a Fishing Community International Journal of Humanities and Social Science, Vol. 1 No. 21 [Special Issue - December 2011]

Rachel M. Amiya, et al. (2014). Perceived Family Support, Depression, and Suicidal Ideation among People Living with HIVIAIDS: A Cross-Sectional Study in the Kathmandu Valley, Nepal. PLOS ONE, DOI: 10.1371/journal.pone.0090959

Ruhani Mat Min. (2012). Rumah Komuniti: Program Pemulihan Penagih Separa Pulih. Universiti Malaysia Terengganu.

Telemu Kassile, et al, Health and social support services to HIVIAIDS infected individuals in Tanzania: employees and employers perceptions, BMC Public Health, 2014, 14:630 doi:10.1186/1471-2458-14-630, http://www.biomedcentral.com/1471-2458/14/630

Wan Rafaei Abdul Rahman et al. (2009). Sokongan Sosial kepada Penagih opiat Dadah dalam Kalangan Kaum Melayu, Cina, dan India Di Malaysia. Jurnal AADK (Malaysian Anti-Drugs Journal) Jilid 5 tahun 2009. ISSN 1985 -1707 